\title{
DESCRIPTION AND EVALUATION OF THE VERMONT DEMONSTRATION PROJECT Final Report
}

Prepared for

U.S. Department of Energy

Office of Utility Systems

By

S. B. White

June 1978 


\section{DISCLAIMER}

This report was prepared as an account of work sponsored by an agency of the United States Government. Neither the United States Government nor any agency Thereof, nor any of their employees, makes any warranty, express or implied, or assumes any legal liability or responsibility for the accuracy, completeness, or usefulness of any information, apparatus, product, or process disclosed, or represents that its use would not infringe privately owned rights. Reference herein to any specific commercial product, process, or service by trade name, trademark, manufacturer, or otherwise does not necessarily constitute or imply its endorsement, recommendation, or favoring by the United States Government or any agency thereof. The views and opinions of authors expressed herein do not necessarily state or reflect those of the United States Government or any agency thereof. 


\section{DISCLAIMER}

Portions of this document may be illegible in electronic image products. Images are produced from the best available original document. 


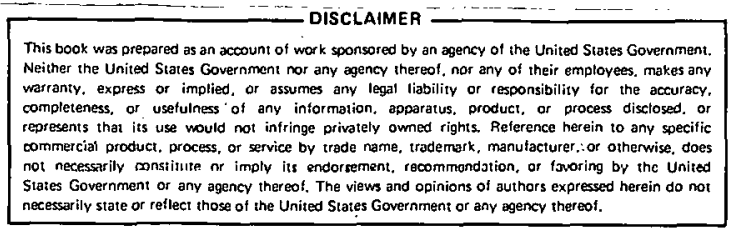

Contract No. EC-77-C-01-8684

June 1978

RTI Project No. 41U-1542-00-04F

\section{Description and Evaluation \\ of}

The Vermont Demonstration Project

Final Report

Prepared for

U.S. Department of Energy

Office of Utility Systems

By

S. B. White 
ABSTRACT............................... ii

1. INTRODUCTION............................... 1

2. DESCRIPTION OF DEMONSTRATION PROJECT............. 2

2.1 Purpose............................. 2

2.2 Participating Agencies................... 2

2.3 Rates................................ 2

2.4 Terms of Customer Participation.............. 3

2.5 Sample Design...................... 3

3. RESULTS AND CONCLUSIONS.................... 6

3.1 Results............................ 6

3.2 Conclusions......................... 6

3.3 Comments............................... 7

REFERENCES............................. 9 


\section{ABSTRACT}

Six nontraditional rates were evaluated by Green Mounta in Power Corporation in a one-year study to determine levels of acceptance and response by residential customers. Participation in the study was voluntary and customer never "lost" money as they were given the choice of paying their bill under the experimental rate or the existing residential rate. Participants (20 on each rate) were selected from customers who responded to a one-day newspaper advertisement for study volunteers. The results indicated that customers on the time-of-day and interruptible rates were relatively satisfied and were able to save money with limited inconvenience. The remaining four rates, which involved some form of demand charge, were generally unacceptable to the customers. The sample design does not enable the projection of effects of implementation of rates on a system-wide basis. 


\section{INTRODUCTION}

In July 1975, Green Mountain Power Corporation initiated a one-year study to determine how residential customers would respond to nontraditional rate structures. Six experimental rates were evaluated. The study did not include a control group. per se; however, data from the Vermont Load Study in the previous year provided a basis for making comparisons of usage patterns.

Chapter 2 provides a description of how the study was developed and carried out. Highlights of the study results and conclusions together with some general comments are given in Chapter 3 . This report draws heavily upon the final report, "Investigation Into The Effects of Rate Structure on Customer Electric Usage Patterns," (1) which provides a detailed account of the study procedures and the analytical findings. 


\section{DESCRIPTION OF DEMONSTRATION PROJECT}

\subsection{Purpose}

This was an exploratory study designed principally to determine customer acceptance and response to nontraditional rates that differed radically in rate form. As evidenced by the sample design and sample sizes employed, the study was not intended to provide statistically valid data for projecting system-wide effects of rate implementation. Rather it was more concerned with identifying for further investigation rate forms which would be acceptable to the customers and be potentially cost-effective.

\subsection{Participating Agencies}

Under the sponsorship of the Department of Energy (formerly the Federal Energy Administration), the study was carried out through the joint efforts of the Vermont Public Service Board and the Green Mountain Power Corporation. The study was conducted within the Green Mountain Power Corporation service area.

\subsection{Rates}

Six nontraditional rates, designed to encourage customers to save money by changing usage patterns, were evaluated. As noted in (1), cost justification was not a major consideration in the rate design. Rather, it was desirable to have rates that ..."volunteer customers could live and work with for one year". The six rates are briefly described below:

a) Off-Peak Rate

The peak hours were $7 \mathrm{a} . \mathrm{m}$. - 9 p.m. daily with price varying as a function of usage. The off-peak hours were $9 \mathrm{p.m.}-7$ a.m. with price again varying as a function of usage but at a lower level. There was a customer charge of $\$ 5.50$ per month.

b) Interruptible Rate

Service to hot water system was interrupted during the periods 9 a.m. - 12 noon and 5 p.m. -7 p.m. A credit of $\$ 5.75$ per month was given to the regular residential rate for the interruptions. 
c) Three-Part Rate

This rate consisted of a customer charge of $\$ 5.50$ per month plus a monthly demand charge (which varied as a function of KW.) and a monthly energy charge (which varied as a function of KWH).

d) Peak Kilowatt Demand Rate

This rate consisted of a demand charge of $\$ 8.40$ per $\mathrm{KW}$ during peak hours ( 9 a.m. - 12 noon) and an energy charge of 1 cent per KWH. There were no customer charges.

e.) Inverted Demand Rate

The following demand charges were imposed: first $3 \mathrm{KW}$ per month o $\$ 4.20$ per $\mathrm{KW}$, next $3 \mathrm{KW}$. $\$ 7.00$ per $\mathrm{KW}$ and all over 6 $\mathrm{KW}$ per month a $\$ 8.40$ per $\mathrm{kW}$. There were no customer or energy charges.

f) Contract Rate

The customer contracted with the company for a specified capacity level. There was no energy charge as long as the contracted demand level was not exceeded. A penalty of $\$ 8.00$ per KW per month was charged for each KW in excess of contracted demand. There was a customer charge of $\$ 5.50 \mathrm{per}$ month.

\subsection{Terms of Customer Participation}

Participation in the study was voluntary. Customers were given the choice each month of paying their bi11. under the experimental rate or under the existing rate; hence, the customer never "lost" money. Customers did not receive direct compensation for participating in the study.

\subsection{Sample Design}

The Green Mountain Power Corporation utilized the newspaper medium for obtaining a presample of residential customers to participate in the rate study. In response to a one-day advertisement for volunteers, 500 of the approximateily 46,000 total residential customers in the service area indicated a willingness to participate. Although this approach for securing a test sample of customers may be quick and easy, its use cannot be statistically justified for making inferences to a population of customers larger than those that actually responded. This is due to the fact that there is no way of knowing how many Green Mountain Power customers did not subscribe to the newspaper or read that particular 
issue; nor how many read the solicitation and chose not to respond. For this study, the population to which inferences can be made consists of those 500 customers who responded positively to the newspaper solicitation.

It seems odd that exactly 500 customers responded to an advertisement. It is not known whether these were the first 500 respondents, all the respondents or some other group. At any rate, the 500 volunteers were stratified into "all electric", "electric hot water", and "other" categories. Some of the volunteers were then eliminated due to remoteness, partial electric heat, inaccessibility of meters, etc. The number of customers excluded within each stratum for each of the above reasons is unknown. From the remaining volunteers, 120 customers were selected for inclusion in the study (20 customers for each of the six rates). Details regarding customers selections were not given in (1) other than that they were selected from each of Green Mountain Power's two service areas chosen for the study. The identity of these two areas, how they were chosen, and the number of residential customers in these two areas are unknown.

The number of customers on test during the second month of the study (August 1975) by stratum for all six rates is given in Table 1. Only 110 of the 120 customers were on test at this point in time. Some of the reasons for the reduction were: inability fo find a time when serviceman could get into the house to change time-of-day meter charts; general misunderstanding; and customers moving.

TABLE 1. Number of Test Customers by Stratum and Treatment

Stratum

A11 Electric

Rate

a. Off-peak

Electric

b. Interruptible

c. Three-part

d. Peak Kilowatt Demand

e. Inverted Demand

f. Contract

TOTAL
8

8

7

7

8

$\frac{1}{39}$

Hot Water

7

12

10

$-10$

8

5

52

\begin{tabular}{ccc}
$\frac{\text { Other }}{5}$ & & $\frac{\text { Total }}{20}$ \\
0 & & 20 \\
2 & & 19 \\
3 & & 20 \\
4 & & 20 \\
5 & & 11 \\
\hline 19 & & 110
\end{tabular}


For comparative purposes, the 1974 Vermont Load Study data were used as a control. This is not considered a valid control group for two reasons. First, the time periods covered by the load study and rate study differ by one year. Secondly, the methods for selecting customers for the two studies are different; hence, the populations represented by the samples are not the same.

Electric usage on each study participant was monitored with a 16day chart recorder which recorded KW demand at 15 minute intervals. The charts were changed every. two weeks.

A few months after the test began, the participants were given an opportunity to provide to the project staff their own. ideas, comments, questions, etc. regarding the rate experiment. About 90 of the 120 customers returned a completed questionnaire. 


\section{RESULTS AND CONCLUSIONS}

\subsection{Results}

Sample data for customers on each of the six nontraditional rates have been summarized by the project staff and the results are given in (1). Basically, the analyses consisted of calculating a series of summary statistics (i.e., group peak load, time of group peak load, average consumption per customer, average demand coincident with group peak (and system peak), average noncoincident demand, load factor, billing information under the regular rate and nontraditional rate, etc.) for each month of the study period for each group of experimental customers. The detailed findings of the individual analyses will not be described here as these results are adequately discussed in (1).

The bottom-1ine results of the Vermont Study may be summarized as follows:

a) Customers on the off-peak and interruptible rates were relatively satisfied and most were able to save money with limited inconvenience. Of these two rates, the interruptible rate appears more acceptable to the utility and customers. Its primary advantage is the inherent ability of the utility to control the system load curve -- a benefit which the off-peak rate does not share.

b) The other four rates, which involve some form of demand charge, were generally unacceptable to the customers. A very large proportion of these customers had bills that were much higher than what they would have paid under the existing residential rate. These higher bills are attributable to the use of high demand appliances, such as clothes dryers, which created high demand charges.

\subsection{Conclusions}

In the interest of clarity and completeness, the study conclusions and recommendations of Green Mountain's Power as reported in (1) are reproduced below.

"Demand charge rates encountered difficulties in meeting customer acceptance. High use appliances, such as clothes dryers, created high demand charges even when not used simultaneously with other appliances. This created high bills and customer dissatis- 
faction. Traditional electric heating equipment, such as electric base board space heating and hot water heaters, are automatically thermostatically controlled, making it impossible for the customers to consistently prevent simultaneous operation. Customers who were able to comply with demand charges installed automatic interlocking switches to prevent the simultaneous operation of high use appliances. In addition to this extra expense to the customer, the cost of metering customers for demand charges by the utility is greater than metering equipment for time-of-day rates, such as the off peak rate. The off peak rate and interruptible rates also showed a potential for removing a larger proportion of load off from the system peak load periods. GMP has concluded that no further research will be done at this time in the area of demand charge rates for residential customers. Off peak time-of-day and interruptible rates appear to be easier to manage for the utility, less expensive to implement, have a greater impact on system load, and also offer the advantage of having a high degree of customer acceptance.

Optional time-of-day off peak rates 11 and 21 were offered to al1 of GMP's customers during June, 1976. (See Appendix VIII for copies of the rates.) At the present time approximately 150 customers are on rate 11, with an additional 28 customers electing to accept the controlled off peak service option and install storage space heating equipment".

\subsection{Comments}

A major weakness in the Vermont study is that the sample design (i.e., utilizing customers who responded to a one-day newspaper advertisement) does not enable inferences to be made to a meaningful population of residential customers within the Green Mountain Power Corporation's service area. Relative to this design fault, it is important to note that the Vermont study was not designed with the intent of obtaining statistically valid data for projecting system-wide effects of implementing any one of the rates utilized in the study. Its purposes as noted 
earlier, were primarily to determine customer acceptance to rates that differed radicaliy in rate form and to identify rate forms deserving further investigation.

Relative to the study objectives, the sample customers used in the study, although small in number, served a useful function as participants in a "screening" test. The conclusions that two of the rates (off-peak and interruptible) were acceptable and offered the potential for further investigation while the remaining four rates were totally unacceptable by the sample of customers are indeed meaningful to rate making agencies even though the sample consists of volunteers from some undefined populations of customers. 


\section{REFERENCE}

(1) State of Vermont Public Service Board and Green Mountain Power Corporation, "Investigations into the Effects of Rate Structures on Customer Electric Usage Patterns." Final report prepared in cooperation with the Federal Energy Administration, March, 1977. 


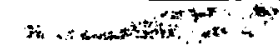

Research Triangle Institute P.O. Box 12194

Research Triangle Park, N.C. 27709 